\title{
Assédio moral: uma análise a partir da percepção de advogados que defenderam trabalhadores assediados
}

\author{
Morgana Zamarchi ${ }^{1}$ \\ Faculdade Meridional (Porto Alegre, RS, Brasil) \\ Vanessa Rissi ${ }^{2}$ \\ Faculdade Meridional (Porto Alegre, RS, Brasil) \\ Lívia Bedin Tomasi ${ }^{3}$ \\ Universidade Federal do Rio Grande do Sul (Porto Alegre, RS, Brasil)
}

\begin{abstract}
O assédio moral tem reverberado em pedidos indenizatórios junto ao poder judiciário trabalhista, e muitos deles têm sido negados. Dentre os motivos, estão as inconsistências apresentadas pelos advogados nos processos judiciais. Desse modo, o objetivo desta pesquisa é analisar a compreensão dos advogados em relação ao assédio moral no trabalho, por meio de um estudo qualitativo com 16 advogados, que defenderam ao menos um processo de assédio moral. Os dados oriundos de entrevistas foram tratados por análise de conteúdo, gerando categorias temáticas a posteriori. Os principais achados indicaram compreensões sobre o assédio moral divergentes do embasamento jurídico e psicológico, em termos de definição e caracterização, bem como quanto à distinção entre assédio e dano moral. Ademais, os advogados informaram os principais meios de prova utilizados, as dificuldades no estabelecimento do nexo causal entre assédio e adoecimento e relataram condutas enganosas que contribuem para fragilizar a noção de assédio moral. Os resultados geram preocupações quanto ao enfrentamento do assédio moral no trabalho, indicando a necessidade de qualificar a compreensão dos advogados.
\end{abstract}

Palavras-chave: Assédio moral, Trabalho, Direito do trabalho.

Moral harassment: an analysis based on the perception of lawyers who defended harassed workers

Moral harassment has reverberated in claims for damages to the labor justice system, and many of them have been denied. Among the reasons are the inconsistencies presented by lawyers in lawsuits. Thus, the objective of this research is to analyze the understanding of lawyers in relation to bullying at work, through a qualitative study with 16 lawyers, who defended at least one case of moral harassment. Data from interviews were treated using content analysis, generating thematic categories a posteriori. The main findings indicated understandings of moral harassment that differed from the legal and psychological basis, in terms of definition and characterization, as well as the distinction between moral harassment and moral damage. Furthermore, the lawyers informed the main means of evidence used, the difficulties in establishing the causal link between harassment and illness, and reported misleading conduct that contributes to weakening the concept of moral harassment. The results raise concerns about coping with bullying at work, indicating the need to improve lawyers' understanding on the subject.

Keywords: Moral harassment, Work, Labor law.

1 https://orcid.org/0000-0002-5598-7610

https://orcid.org/0000-0002-1895-9354

3 http://orcid.org/0000-0002-7472-2255 


\section{Introdução}

$\mathrm{O}$ assédio moral no trabalho (AMT) é um fenômeno reconhecido pela Organização Mundial da Saúde como um comportamento irracional, abusivo e processual que ocorre no ambiente de trabalho (Cassito et al., 2004). As evidências recentes produzidas pela literatura convergem em considerar que as condutas assediosas de caráter violento e abusivo estão implícitas na engrenagem dos processos e políticas organizacionais (Antunes \& Praun, 2015; Araújo, 2009). Do ponto de vista jurídico, concebe-se que o AMT ofende os direitos fundamentais dos trabalhadores, podendo, inclusive, implicar danos morais, físicos, psíquicos e existenciais (Araújo, 2009).

Os estudos iniciais sobre o AMT datam da década 1980, quando o pesquisador alemão radicado na Suécia Heinz Leymann introduziu o termo para descrever condutas agressivas e repetidas no trabalho. Pouco depois, em 1998, a psiquiatra e psicanalista francesa Marie-France Hirigoyen (2002) popularizou o tema, considerando o AMT como uma conduta abusiva que se manifesta por comportamentos, palavras, atitudes e/ou gestos e que gera danos à personalidade, dignidade, à integridade física e psíquica, além de degradar o ambiente de trabalho. No Brasil, o termo foi apresentado pela médica do trabalho Margarida Barreto, em 2000, a partir de sua dissertação de mestrado (Barreto, 2000). Entretanto, atribui-se a Freitas (2001) a primeira publicação nacional em periódico científico, intitulado Assédio moral e assédio sexual: faces do poder perverso nas organizações.

As principais características atribuídas ao conceito de assédio moral são subdivididas em duas categorias: uma que compõe elementos objetivos e outra os subjetivos, segundo afirma Soboll (2017). Os fatores objetivos compreendem atos hostis insistentes, repetitivos e duradouros, que podem ser evidentes ou sutis, manifestos por gestos, palavras, mensagens ou por processos organizacionais. Os subjetivos estão relacionados aos danos à dignidade do sujeito, ao sentimento de humilhação e ao constrangimento, os quais podem causar prejuízos à saúde e degradam o ambiente de trabalho. A partir das características iniciais, o conceito de assédio moral é capaz de representar dois tipos de assédio: o moral interpessoal e o organizacional, cuja classificação permite um olhar apurado sobre os processos organizacionais que o originam ou $\mathrm{O}$ permitem. A propósito, o assédio organizacional consiste nas ocorrências contínuas de violência, imbricadas nas políticas e procedimentos organizacionais e de gestão, ou delas decorrentes. $\mathrm{O}$ assédio moral interpessoal contempla as situações de perseguição, pessoalizadas, em que é possível, geralmente, identificar o agressor e que tem por objetivo a exclusão e prejuízo da vítima (Soboll, 2017).

Há duas abordagens teóricas principais que analisam o AMT do ponto de vista de sua casuística. Uma delas, a tradicional e já superada pela abordagem psicossocial, compreende uma perspectiva de vítima-agressor, explicando e buscando soluções no âmbito psíquico e individualista. Transcendendo essa análise individual, na abordagem psicossocial, o AMT é concebido como um problema relacionado à organização social do trabalho. Isso não significa que os fatores individuais sejam completamente desconsiderados, porém, esses sempre se relacionam com a organização do trabalho (Soboll, 2017). Mesmo que a experiência de assédio possa estar personificada em um superior hierárquico, ela encontra-se em conformidade com as práticas organizacionais (Antunes \& Praun, 2015).

O assédio atende, portanto, enquanto ferramenta de gestão institucionalizada (Antunes \& Praun, 2015), aos ímpetos do capitalismo flexível, caracterizado por uma morfologia de trabalho perversa e violenta. $O$ culto ao desempenho produtivo máximo, sem erros, o estímulo à competitividade interna e a ideologia da competência são algumas das características morfológicas de um trabalho cruel, que tem no assédio moral uma de suas expressões (Vasquez, 2018).

O trabalho é constituinte da identidade humana (Vasquez, 2007). Logo, a experiência do AMT, fortalecida pela organização flexível do trabalho, viola este significado de reconhecimento do sujeito e impacta, sobremaneira, a sua integridade física e psíquica (Vasquez, 2018). Não obstante, a literatura especializada tem indicado a associação do AMT a sinais e 
sintomas de adoecimento de trabalhadores de diferentes categorias profissionais e em várias partes do mundo. Trabalhadores espanhóis considerados vítimas de assédio moral apresentaram maiores índices de sintomas depressivos em comparação aos que não foram assediados (Figueiredo-Ferraz et al., 2013). Sintomas de estresse e vivências de assédio moral apresentaram correlação positiva em uma amostra de trabalhadores de instituições de ensino superior paquistaneses (Qureshi et al., 2013), assim como trabalhadores belgas indicaram percepção deteriorada da saúde em razão do AMT (Notelaers et al., 2018). No judiciário brasileiro, sintomas de ansiedade, estresse e depressão foram autorrelatados pelos servidores alvos de AMT (Pooli \& Monteiro, 2018).

Ainda que as práticas assediadoras sejam antigas e antecedentes a qualquer rearranjo produtivo e de trabalho ocorrido ao longo da história (Antunes \& Praun, 2015), tem se observado que as demandas jurídicas trabalhistas, para casos de AMT, têm aumentado nos últimos anos (Arenas \& Piccinini, 2012; Malhadas et al., 2015; Pamplona-Filho, 2018). Por um lado, a ofensiva neoliberal capitalista, desde a década de 90, vem produzindo cenários de precarização do trabalho, cujos modelos de gestão abusivos e cruéis (Casulo, 2018) resultaram na ampliação vigorosa dos casos de AMT (Antunes \& Praun, 2015). Por outro, do mesmo modo com que as organizações funcionam com base em processos de gestão perversos, denotam-se dificuldades de enfrentamentos assertivos ao AMT, especialmente no que diz respeito ao âmbito da prevenção (Glina \& Soboll, 2012), permitindo o seu avanço desenfreado.

No ordenamento jurídico trabalhista brasileiro, ainda não há legislação específica que regulamente a questão do assédio moral no trabalho (Pretti, 2021). Por ora, o enfrentamento do fenômeno está fundamentado no respeito à dignidade humana, conforme os termos do art. $1^{\circ}$, inciso III, da Constituição da República de 1988, que reprime a conduta abusiva e sugere a indenização das vítimas, como forma de retratação. Em adição, nos casos de assédio moral, tomase a Constituição Federal, nos termos do artigo 5ㅜㅡ, incisos V e X, em que as pessoas que sofrerem agravos têm direito a uma resposta proporcional aos danos sofridos, sejam eles danos materiais, morais ou de imagem, assegurando o direito a indenização. Também se considera para finalidades jurídicas que o empregador possa sempre ser responsabilizado, na medida em que é seu o compromisso da criação e manutenção de um ambiente digno e saudável de trabalho, conforme o artigo 157 da Consolidação das Leis Trabalhistas (Delgado, 2018).

Ainda assim, o estado do Rio de Janeiro destaca-se no cenário brasileiro como o primeiro a aprovar uma lei estadual, a de no 3.921, que proíbe a ocorrência do assédio moral em todos os órgãos, setores, autarquias e fundações daquele estado. $\mathrm{Na}$ esfera federal, assim como nas estaduais e municipais, há diversos projetos de lei (PL) em tramitação. A exemplo, o PL no 4.742 propõe que o assédio moral seja incluído no Código Penal Brasileiro, com pena prevista de detenção (três meses a um ano) e multa ao assediador (Pretti, 2021).

Geralmente a indenização por danos morais em decorrência das condutas de assédio tem sido solicitada em razão das vítimas não encontrarem suporte para resolução desse problema nas empresas e instituições (Hirigoyen, 2002). Em alguns casos, o trabalhador é culpabilizado, sob a alegação da empresa de ser um sujeito emocionalmente frágil (Rissi et al., 2016). Sem a adequada mediação por parte das organizações, os profissionais advogados passam a fazer parte da cena principal de enfrentamento ao assédio moral, na medida em que, por meio de ações judiciais, buscam reparar os danos sofridos pelas vítimas, através de indenização (Soboll, 2017). Sendo assim, este artigo demonstra relevância ao focar nas percepções dos advogados, entendidos como essenciais no combate ao assédio moral, notadamente nos casos em que falharam as intervenções no contexto em que ocorreram as experiências de AMT.

Independente do contexto de enfrentamento do assédio moral (na empresa ou processo judicial), parte-se do pressuposto de que é imprescindível o estabelecimento, com rigor, da sua compreensão conceitual e demais características definidoras pelos profissionais envolvidos. Imprecisões podem flexibilizar o termo, descaracterizar as vivências e, por fim, prejudicar os trabalhadores que se deparam com a experiência do assédio moral (Malhadas et al., 2012).

No caso de advogados, se não bem compreendidas as nuances conceituais e elementos caracterizadores do assédio moral, é possível que as ações judiciais não logrem êxito, outro 
argumento para a importância de investirmos em pesquisas com este público. Não obstante, a maioria dos processos que chegam na justiça do trabalho não tem obtido sentença favorável aos trabalhadores. A rigor, observou-se em estudo realizado por Valadão e Mendonça (2015) que, dentre 243 processos judiciais analisados, $80 \%$ dos casos obtiveram sentença improcedente, seja pela dificuldade da comprovação ou por não se tratar de situações características de assédio.

Porquanto, a partir da problematização exposta, esta pesquisa propõe-se a analisar, do ponto de vista qualitativo, a compreensão de advogados sobre o assédio moral no trabalho. Este artigo é proveniente de dissertação de mestrado desenvolvida junto a um Programa de Pósgraduação stricto sensu em Psicologia.

\section{Método}

Participaram da pesquisa 16 advogados, a partir dos seguintes critérios de inclusão: (a) que tivessem defendido ao menos um processo judicial que requeria indenização por assédio moral no trabalho; (b) que o(s) processo(s) tivesse sido julgado(s) junto ao Tribunal Regional do Trabalho (TRT) 4aㅡ região. Para determinar o número de participantes, foi utilizado o critério de amostragem por saturação (Minayo, 2014), ou seja, foi suspensa a inclusão de novos participantes quando as informações fornecidas por eles pouco acrescentavam ao material já obtido.

Dentre eles, onze advogados eram do sexo masculino e cinco do sexo feminino, com idades entre 26 e 54 anos, todos atuantes em escritórios privados de advocacia. O tempo médio de atuação na profissão era de 10 anos. Os participantes eram de cinco cidades de pequeno e médio porte do Rio Grande do Sul, sendo a maior delas com cerca de 200 mil habitantes. Por questões éticas relacionadas à possível identificação dos participantes, a designação das cidades não será mencionada. Os participantes são nomeados neste estudo pela letra "A", seguida de um algarismo numérico (de 1 a 16).

Para a coleta de dados, utilizou-se um roteiro de entrevista semiestruturado composto por dois blocos temáticos: dados sociodemográficos e compreensão sobre o assédio moral no trabalho. O roteiro foi elaborado com base em Soboll (2017) e Hirigoyen (2002), privilegiando os seguintes temas: definição e caracterização do assédio, a questão da prova, os casos defendidos e a mercantilização do assédio moral.

O contato inicial, com os nomes de potenciais participantes, ocorreu através de buscas em sites que relacionavam listas de contatos de advogados atuantes na região de abrangência do TRT4. Aleatoriamente, por sorteio, identificava-se um nome. Por telefone, eram explicados os objetivos da pesquisa, a forma de participação e questionava-se se o(a) advogado(a) atendia aos critérios de inclusão ao estudo. Na sequência, realizava-se a combinação acerca do horário e local da entrevista. Aos cinco primeiros participantes foi perguntado se conheciam outros profissionais que se adequassem aos critérios da pesquisa, e o contato para convidá-los a integrar o estudo ocorreu igualmente, configurando-se, por conseguinte, a amostragem por bola de neve. Todas as entrevistas individuais foram realizadas nos escritórios de advocacia dos participantes, entre os meses de junho e julho de 2018, e duraram, em média, 45 minutos cada.

As entrevistas foram gravadas em áudio com a permissão dos participantes e posteriormente transcritas na íntegra, para serem submetidas à análise de conteúdo temática. Proposta por Bardin (2011), a referida técnica considera o acesso a diversos conteúdos presentes em um texto, explícitos ou não, circunstância a ser considerada não apenas no tocante à semântica da língua, mas também quanto à interpretação do sentido que um sujeito atribui às mensagens. Construíram-se categorias temáticas a posteriori a partir dos dados coletados nas entrevistas. A decisão pela estruturação das categorias seguiu o critério da frequência de respostas.

Conforme estabelecem as Diretrizes e Normas Regulamentadoras de Pesquisa Envolvendo Seres Humanos, Resoluções do Conselho Nacional de Saúde (CNS) no 466/2012 e CNS no 510/2016, este estudo foi submetido ao Comitê de Ética da Faculdade Meridional IMED e aprovado sob o número 2.661.260. Os participantes assinaram um Termo de Consentimento 
Livre e Esclarecido, no qual estavam cientes dos riscos mínimos e benefícios da pesquisa, bem como da garantia de sigilo e confidencialidade dos dados.

\section{Resultados e discussão}

A categorização e análise das entrevistas fez emergir três categorias temáticas, a saber: a compreensão sobre o assédio moral; a comprovação do assédio moral e as condutas inadequadas e o decorrente descrédito da noção de assédio moral.

\section{A compreensão sobre o assédio moral}

Esta categoria objetivou identificar como está estabelecida a compreensão de AMT pelos entrevistados. Os advogados relataram de que modo definem o assédio moral e quais elementos são utilizados na sua caracterização.

De modo uníssono, os advogados definiram que o AMT corresponderia a qualquer prática que tenha como consequência, ao assediado, o sofrimento: "Toda ação ou omissão que causa um sofrimento interno, que não necessariamente seja através de um xingamento, pode ser uma exclusão, perseguição, um afastamento do empregado, que faz que se sinta humilhado, diminuído, ofendido, um sofrimento interno dele" (A3). Não há dúvidas de que o assédio moral implique constrangimento, humilhação ou vergonha. Inclusive, ao descrever os critérios obrigatórios para a caracterização adequada do assédio moral, Soboll (2017) introduz a noção da dimensão subjetiva do ato assedioso. Desse modo, sob esta perspectiva específica, considera-se que os advogados entendam que o AMT mobiliza a vivência de humilhação.

Contudo, ao tomar-se o trecho anterior, verifica-se que o profissional verbaliza que AMT seria "toda ação ou omissão" que culmine em prejuízos de ordem subjetiva. A partir dessa compreensão, qualquer relato de humilhação ou ofensa definiria a ocorrência de AMT. Este ponto de vista sobre condutas assediadoras representa uma inadequação importante da parte dos advogados e que pode ser um dos elementos explicativos para que tantos processos judiciais não sejam reconhecidos como assédio moral. A literatura é clara ao apontar que relatos de humilhação no contexto de trabalho não são sinônimos de assédio moral (Soboll, 2017), do mesmo modo que há incontáveis jurisprudências apontando na mesma direção (Malhadas et al., 2015).

Ainda assim, procurou-se investigar mais profundamente a compreensão dos advogados sobre as ações objetivas que representariam o assédio moral no trabalho, até mesmo em razão de que a dimensão objetiva é essencial no âmbito jurídico, ao tomar-se a necessidade de comprovação dos atos e dos danos deles provenientes em processos judiciais (Malhadas et al., 2015). Com relação a esse tema, os advogados indicaram as situações objetivas de assédio que costumam ser relatadas com maior frequência, pelos trabalhadores, em seus escritórios de advocacia: ". . . cobranças excessivas por parte dos superiores, cobrança excessiva até de forma áspera, palavrões, muitas vezes, ou com palavras mais fortes, depreciativas ..." (A6).

As situações narradas pelos advogados até poderiam ser consideradas como assédio moral do tipo organizacional, na medida em que esse tipo de assédio, na acepção de Gosdal (2017), contempla práticas inseridas nas estratégias de gestão, por meio de pressões, humilhações e constrangimentos, que visam ao engajamento às políticas e metas da empresa, para, enfim, aumentar a produtividade e resultados. Entretanto, cabe alertar que, para serem efetivamente caracterizadas como AMT, outros critérios devem estar presentes, tais como a recorrência das práticas assediadoras, o que é apresentado na literatura desde as publicações clássicas, como a de Hirigoyen (2002), até as contemporâneas, a exemplo de Gosdal (2017) e Soboll (2017). Porém, nas verbalizações dos advogados não há menção a nenhuma outra característica, o que revela mais um aspecto ignorado por esses profissionais quanto aos limites definidores do assédio moral.

Este achado referente à ausência de uma análise que contextualize a recorrência das práticas assediosas pode ser considerado como mais uma variável que contribui para que sejam 
indeferidos os processos judiciais que pleiteiam o reconhecimento do AMT. Ademais, o fato de advogados considerarem irrestritamente todo ato que cause alguma forma de constrangimento no contexto de trabalho como AMT pode ser um dos fatores que contribuam para o alto número de demandas judiciais. A propósito, Bender (2017) indica que, depois do primeiro caso de assédio moral julgado no Brasil, no ano de 2003, o crescimento da judicialidade foi exponencial. Ainda assim, outros elementos devem ser adicionados à compreensão sobre o aumento de supostos casos de AM instaurados na justiça do trabalho, em meados dos anos 2000. Foi no mesmo período em que se passou a evidenciar com maior frequência os modelos de gestão abusivos e violentos, não raramente naturalizados e negligenciadas, como demonstram Antunes e Praun (2018). Do mesmo modo, os trabalhadores passaram a obter maior conhecimento sobre o AM, no Brasil, em grande parte, por intermédio das discussões fomentadas pelo estudo de Barreto (2000), considerado como pioneiro por Soboll (2017).

Outra questão evidente nos discursos dos advogados entrevistados, quando indagados sobre a definição de AMT, foi a presença da expressão "abuso do poder diretivo": "Existe o poder diretivo e o assédio moral no trabalho. Hoje, quando o empregador ultrapassa os limites desse poder diretivo e passa a constranger seu funcionário, pode estar ocorrendo o assédio moral" (A1). Essa expressão está contida nos artigos 2o e 3ํ da CLT, diante da definição de empregador como aquele que, dentre outras responsabilidades, detém o poder diretivo (Decreto-Lei no 5.452, 1943). Quando o poder diretivo se excede, considera-se a ocorrência do ato ilícito, definido pelo artigo 187 do Código Civil Brasileiro, o qual é passível de indenização, conforme artigo 927 do mesmo código, apontam Guedes et al., (2010). Sendo assim, do ponto de vista jurídico, o assédio moral pode ser enquadrado como um ato de abuso do poder diretivo pelo empregador.

Porém, a conexão estabelecida pelos advogados, nesta pesquisa, entre o assédio moral e o abuso do poder, deflagra uma tendência a considerar o AMT numa perspectiva individualista que culpabiliza o assediador. Esse ponto de vista ignora a concepção predominante na literatura, aqui representada por Casulo (2018), de que o assédio moral esteja enraizado nas políticas e processos organizacionais a partir de uma morfologia de trabalho capitalizado e flexível, marcado por métodos de gestão aviltantes. Evidentemente que fatores individuais podem vir a interferir nos processos de assédio moral, como lembra Soboll (2008). Todavia, cabe alertar que a tendência demonstrada pelos advogados em perceberem o assédio como um comportamento abusivo individualizado suaviza a responsabilidade da organização, que, em conformidade com Soboll (2017) e Gosdal (2017), deve sempre ser responsabilizada.

Ao definirem o assédio moral, os advogados enfatizaram, também, a periodicidade com que ocorrem os comportamentos de assédio moral: "Eu acho que tem que ser atitudes reiteradas, por exemplo, eu tive casos que aconteceu um fato isolado aí eu não considero que seja um assédio moral" (A6). Apesar disso, alguns referiram divergir desta percepção, na medida em que o assédio poderia caracterizar-se por um ato isolado: ". . . claro tem que ser analisado o caso, porque um único evento pode ser assédio" (A4). Notou-se, assim, que não houve entendimento homogêneo por parte dos advogados em referência a um dos elementos definidores de AMT - a periodicidade dos atos - que, não obstante, já foi amplamente discutido pela literatura.

A propósito, para que fosse caracterizado o assédio, inicialmente Leymann (1996) considerava que as atitudes de hostilização ocorressem com frequência semanal e que se mantivessem por seis meses. Atualmente, afirma Soboll (2017), não se valoriza o tempo em que duram as atitudes assediadoras, mas enfatiza-se o caráter processual, fator que atribui cronicidade e gravidade ao assédio moral. Articulado ao contexto organizacional, a questão essencial do assédio moral está no fio condutor das práticas assediadoras - a própria organização - que, a todo momento, em qualquer tempo e por qualquer período, propiciará ocorrências de AMT (Antunes \& Praun, 2015). Diante deste panorama histórico cunhado por Leymann (1996) e Soboll (2017), além de Antunes e Praun (2015), que culmina no consenso técnico científico de que o assédio moral é um processo, os achados desta pesquisa sinalizam outro desacerto dos advogados a colaborar com peças processuais mal embasadas.

Ao definirem o assédio moral, os advogados evidenciaram a intenção de causar prejuízo ao trabalhador como um elemento a ser considerado: “. . . para atingir o funcionário . . . muitas 
vezes é usado o assédio para que o empregado se demita, às vezes é usado para atingir por algo pessoal o funcionário" (A2). De outro modo, também houve considerações que tomaram a possibilidade da ocorrência de assédio moral como um ato não intencional: "Toda conduta mesmo que involuntária que cause humilhação ..." (A3).

Assim como no entendimento dos advogados, a intencionalidade é um critério considerado controverso na caracterização do assédio moral, segundo Soboll, Miara e Moscalewsky (2017). Por um lado, entende-se que o assédio moral é premeditado e quem o pratica tem consciência do que está fazendo, a quem está fazendo e a razão de estar atingindo (Heloani, 2016; Hirigoyen, 2002). Por outro, é visto apenas como um critério complementar de caracterização do assédio. Apesar disso, cabe a observância de que os advogados não refletiram, em tempo algum das entrevistas, sobre a importância de entender o assédio moral a partir do caráter processual recomendado pela literatura, e que, portanto, para evitar equívocos, as análises dos casos relatados por seus clientes deveriam sofrer severo processo diagnóstico. Este indício da pesquisa amplia o rol de inadequações dos entrevistados acerca do AMT.

Além de revelarem desconhecimento quanto aos critérios identificadores e caracterizadores do AMT, alguns advogados demonstraram outras severas incompreensões: “. . . é a questão do acidente de trabalho que pode gerar o assédio moral, quando tem, digamos, uma amputação de membros" (A13). Do mesmo modo, foi tomado em equivalência a um dano qualquer sofrido no ambiente laboral: ". . . o assédio moral, ele não é um dano que se verifica imediatamente, ele é um dano que se prorroga, que se estende no tempo ..." (A8). Um acidente de trabalho pode repercutir em danos ao trabalhador vitimado, jamais em assédio moral, já que se referem a institutos diferentes. Uma conexão possível entre um acidente de trabalho e o assédio seria se a empresa adotasse atos configuradores de assédio em relação a um trabalhador acidentado na expectativa de que ocorra um pedido de demissão, segundo sugere Gosdal (2017). $\mathrm{Na}$ mesma acepção equivocada, o assédio moral não é equivalente a um dano, como apontou A2. O assédio pode causar um dano, explica Pamplona-Filho (2018).

Portanto, ambos os trechos declarados pelos profissionais da advocacia sinalizam pouco (ou nenhum) investimento no estudo da temática do AMT que pudesse fundamentar as ações processuais com qualidade e rigor técnico. Ressalta-se que o contingente de conhecimento relevante produzido sobre o AMT, no Brasil e no mundo, é substancial. E não se trata apenas de conteúdos concentrados pela área da Psicologia. Segundo Rezende (2008), o Direito tem se preocupado com a correta compreensão do AMT, e as publicações de precursores como Araújo (2008), Freitas (2001) e Guedes (2004) corroboram a afirmação.

No transcorrer das entrevistas também se discutiram os possíveis direcionamentos do AMT. Sabe-se que assédio pode ocorrer em qualquer relação de trabalho, não sendo necessário haver uma relação de poder. Isso significa que colegas numa mesma posição hierárquica podem assediar-se mutuamente, assim como um subordinado pode vir a assediar um superior hierárquico (Soboll, 2017). A esse respeito, os dados da pesquisa demonstraram que alguns advogados não consideram a possibilidade do assédio horizontal (entre colegas) ou vertical ascendente (do subordinado para o superior): "De regra, o assédio moral parte do empregador e não vejo nada além disso, na verdade" (A1). Entretanto, outros demonstraram estar atentos às diversas fontes assediadoras: "então, é na linha vertical de empregado para empregador, é na linha horizontal entre trabalhador e colega trabalhador, e raras vezes ocorre também o assédio de empregados para seus superiores ..." (A2).

O fato de alguns advogados somente conceberem o assédio numa relação de subordinação contribui para a invisibilidade do fenômeno sob esse ponto de vista. Outrossim, estudos revelam a ocorrência de assédio horizontal entre trabalhadores da educação (Ventura et al., 2018), de instituição jurídica (Pooli \& Monteiro, 2018) e na área da saúde (Rissi et al., 2013). Do mesmo modo, o assédio advindo de subordinados na direção dos gestores também é uma realidade, mesmo que menos frequente (Lima \& Souza, 2015). Ignorar o assédio moral horizontal ou ascendente indica uma visão míope dos advogados sobre a dinâmica desta forma de violência ocupacional. 
Tão importante quanto os aspectos discutidos até então, do ponto de vista jurídico, destaca-se a relação indissociável entre o assédio e o dano moral, para delimitar os contornos do assédio moral. O que torna o assédio moral passível de indenização e, portanto, confere à vítima o direito de buscar um advogado que a defenda mediante processo judicial é o dano moral decorrente do(s) ato(s) assedioso(s). Apesar disso, alguns advogados entrevistados demonstram que sequer distinguem assédio moral e dano moral: "O assédio moral é uma espécie do gênero do dano moral ..." (A1); "O dano moral seria uma atitude única e o assédio moral é aquela atividade repetida, tipo uma conduta repetida, reiterada" (A9). Os desacertos então evidenciados são muito relevantes, especialmente porque, segundo Pamplona-Filho (2018), a noção de assédio moral definitivamente não permite confusão com o dano moral.

Por fim, explica-se que na acepção jurídica o assédio moral pode gerar, por consequência, o dano moral (ou outros danos) por atingir a honra, a dignidade, a imagem da pessoa e repercutir em sua saúde física e/ou mental (Gosdal, 2017; Guedes et al., 2010; Pamplona-Filho, 2018). A dificuldade de distinção do assédio moral e do dano moral constatada nesta pesquisa corrobora o estudo de Malhadas et al. (2015), que ainda sentenciam que esse tipo de erro por parte dos operadores de direito faz com que reais danos provenientes de assédio moral caiam na "vala comum" dos "danos morais", sem a preocupação de evidenciar-se as implicações na esfera psíquica do indivíduo e demais consequências, o que facilita a sua banalização (Malhadas et al., 2015).

\section{A comprovação do assédio moral}

Nesta categoria, o foco foi o entendimento dos advogados sobre a comprovação do assédio moral. Dessa maneira, destacaram-se dois pontos: a dificuldade em comprovar a ocorrência do assédio moral, assim como a dificuldade no estabelecimento do nexo causal, que se refere, em conformidade com Battistelli et al., (2011), à comprovação da relação existente entre a consequência (o adoecimento, a exemplo) e a sua causa (o ato assedioso).

As provas apresentadas pelos advogados, na expectativa de comprovar o assédio moral, são de vários tipos: “. . . em síntese, gravações audiovisuais, gravações de vídeo, troca de mensagens e a prova testemunhal" (A15); “. . . tinha fotos da porta do banheiro e uma testemunha..." (A7).

A prova testemunhal é a mais utilizada nos casos de assédio moral. Provas físicas como registro de e-mails, mensagens via celular, atestados de saúde, fotografias, entre outras, são mais difíceis de ser reunidas, visto que o agressor nem sempre se expressa de forma que a vítima possa reunir indícios concretos (Valadão \& Mendonça, 2015).

Todavia, ainda que a prova testemunhal seja a mais frequentemente apresentada pelos advogados, os atos de assédio são praticados, muitas vezes, com discrição pelo algoz, o que foi relatado pelos advogados como um elemento complicador para se constituir provas qualificadas: “. . . geralmente a pessoa que comete o assédio, ela toma uma certa precaução para não deixar testemunhas né?” (A11); “. . . ocorrem entre o empregado e o empregador, e as outras pessoas não presenciam, então você tem a dificuldade de provar ..." (A15).

Além disso, a resistência dos colegas ou ex-colegas de trabalho em prestar seu depoimento em juízo, principalmente os que ainda mantêm vínculo empregatício com a empresa, representa outra barreira para constituição das provas testemunhais: “. . . é difícil encontrar quem se disponha a fazer a prova, a menos que seja alguém que já tenha saído da empresa, ou que também esteja sofrendo assédio e não tenha maiores problemas de falar disso por estar sofrendo (A1); “. . . normalmente um funcionário não vai nessas audiências com medo de represálias da empresa ...” (A14). Essa concepção dos advogados está em consonância com as afirmações de alguns autores, como Arenas e Piccinini (2012) e Lima et al. (2014), segundo os quais poucos colegas de trabalho concordam em testemunhar, em razão da relação direta com o assediador e por sentirem medo de sofrer consequências negativas, serem demitidos ou mesmo tornarem-se a próxima vítima. Pode-se tomar Hirigoyen (2002) para auxiliar na compreensão das frequentes 
negativas dos colegas em prestar depoimento, de modo que isso decorre dos mecanismos organizacionais que controlam o comportamento e a subjetividade dos trabalhadores.

Não obstante, o caráter voluntário do testemunho no âmbito da justiça trabalhista, ou seja, não há intimação ou notificação para as testemunhas comparecerem em audiência, também contribui para reforçar a negativa de muitas pessoas em testemunhar casos de assédio moral. Adorno Júnior (2010) explica essa questão ao referenciar o artigo 825 da CLT como aquele que define que as testemunhas de processos trabalhistas podem ser convidadas pelas partes, sendo livre seu comparecimento.

A par das dificuldades comprobatórias, incluem-se as que se relacionam ao nexo causal entre o adoecimento e o AMT: "Muito difícil de nós conseguirmos provar, mesmo que estejam com o problema depressivo e de que isso tenha sido ocasionado pelo assédio moral" (A6); “. . . teve a perícia psicológica, mas o perito disse assim 'pode ser ou pode não ser"” (A15). Para melhor compreensão, retoma-se que nexo causal corresponde ao vínculo existente entre a conduta do autor e o resultado por ele produzido, constituindo-se elemento indispensável para a responsabilidade civil (Cavalieri Filho, 2012). O assédio moral, por si só, gera o direito à reparação pelo dano moral sofrido, desde que restem claras as provas que evidenciam as ofensas morais, segundo indicam Battistelli et al. (2001). Entretanto, se, além disso, a saúde da vítima for prejudicada em decorrência do assédio e houver pedido de indenização, no intuito de evidenciar esse nexo causal, o juiz poderá nomear um perito, o que inclui o trabalho de médicos e psicólogos (Evangelista, 2000; Heloani, 2005).

Dessa maneira, os advogados entrevistados manifestaram as dificuldades para que se consiga comprovar que o assédio moral resultou em adoecimento: "Muito difícil de nós conseguirmos provar, mesmo que estejam com o problema depressivo e de que isso tenha sido ocasionado pelo assédio moral" (A6); “. . . teve a perícia psicológica, mas o perito disse assim "pode ser ou pode não ser" (A15). A dificuldade relatada pelos advogados confirma as pesquisas de Jacques (2007), Malhadas et al. (2015) e Pamplona-Filho (2018), a partir das quais compreende-se que a complexidade envolvendo o estabelecimento do nexo causal (assédio versus doença) é reconhecida tanto pela literatura da área do direito quanto pela da psicologia. Ainda complementam que, se é dificultosa a tarefa de provar que o assédio moral ocorreu, em virtude de suas nuances muitas vezes silenciosas, mais ainda será a de comprovar um consequente dano à saúde, especialmente de ordem psíquica.

\section{Condutas inadequadas e o decorrente descrédito da noção de assédio moral}

Nesta categoria, discorre-se sobre condutas inadequadas e antiéticas assumidas pelos advogados diante dos processos judiciais, que tendem a tornar o fenômeno do assédio moral desacreditado e enfraquecido perante os que julgam os processos trabalhistas.

Os advogados admitiram que incluem o assédio moral em processos judiciais trabalhistas, de modo indevido, numa clara tentativa de alcançar um valor indenizatório maior pelo dano moral: “. . . vamos colocar junto o assédio moral, 'se passar, passou', então isso acaba virando um produto, uma mercantilização ..." (A2). Pamplona-Filho (2008) apontou que condutas como a exemplificada por A2 não são incomuns, e ainda sugere que falsas alegações de assédio não só resultam em indeferimentos das decisões judiciais como desestabilizam a luta pelo reconhecimento do assédio moral no trabalho como um grave e frequente problema organizacional.

Na mesma lógica, outro advogado referiu que a inclusão do pedido de indenização por dano moral, sem que o assédio moral tenha ocorrido, é uma manobra jurídica que visa à tentativa de não incisão de impostos trabalhistas sobre o processo:

todo pedido, tem que fazer por base naquilo que a pessoa pediu na justiça do trabalho, e isso vai gerar uma tributação, por exemplo, se tu vai pagar hora extra, a hora vai ser tributada, tu vai pagar para funcionário um determinado valor de horas extras, vai ter o INSS que vai incidir ali, e tu vai ter que recolher. Aí, às vezes, inclui-se esse dano moral, que viria de um assédio, para 
chegar na audiência e falar 'não, se a gente fizer o acordo hoje, a gente coloca tudo em dano moral e não vai ter imposto para a empresa (A10).

A conduta tomada por A10 é viabilizada em razão de que o dano moral, implícito numa ocorrência de assédio moral, ao ferir a personalidade, integridade física e mental, causa prejuízo moral e não material, o que o caracteriza como dano extrapatrimonial. A indenização, nessa circunstância, não visa ao lucro, mas, sobremaneira, pretende punir o assediador e reparar a vítima pelo dano sofrido (Nelson \& Teixeira, 2017). Portanto, conforme a lei que regulamenta a Previdência Social (Lei no 8.212/91), o dano moral não incide em impostos trabalhistas por ser de natureza indenizatória. Por outro lado, verbas designadas a retribuir o trabalho, como horas extras, por exemplo, são passíveis da incidência do imposto (Lei no 8.212/1991).

Sobremaneira, os relatos dos advogados A2 e A10 revelam que suas práticas são antiéticas, na medida em que as ocorrências incluídas nos processos são falsas alegações que visam ao enriquecimento ilícito, conforme Malhadas et al. (2015). Ademais, as autodeclarações indicam a necessidade de ampliarem-se as discussões sobre a ética profissional nesse contexto. Não obstante, diante da divulgação do novo Código de Ética do Direito no Brasil (Coêlho, 2017), observa-se que a valorização da profissão se faz por dois meios, não excludentes: a defesa das prerrogativas e a observância dos padrões éticos, acrescentando que cabe ao advogado a atuação a partir de parâmetros dignos. Por fim, destaca-se o entendimento de Malhadas et al. (2015) sobre o fato de que a inobservância de padrões éticos de conduta por parte dos advogados compromete a luta dos trabalhadores vitimados pelo assédio moral, que buscam na justiça trabalhista um alento para a violência que sofreram.

\section{Considerações finais}

Este estudo pautou-se nas compreensões e percepções dos profissionais advogados em relação ao assédio moral no trabalho. Os achados indicaram as percepções dos participantes quanto à definição e características do assédio moral, relativas à questão da comprovação da ocorrência do assédio e do nexo causal entre assédio e adoecimento, bem como possibilitaram o desvelar de práticas antiéticas promovidas pelos próprios advogados.

Em síntese, o assédio moral foi compreendido do ponto de vista de sua definição e caracterização, a partir de uma série de equívocos. Dentre eles, o AMT corresponderia a qualquer ato que implique humilhação ou experiência correlata. Na caracterização do assédio pelos advogados não foram considerados os elementos reconhecidos pela literatura como imprescindíveis para o seu delineamento. Também se constatou que alguns advogados sequer distinguem o assédio moral do dano moral. Da perspectiva da comprovação do assédio moral e de suas consequências danosas, o entendimento predominante dos advogados é de que há muitas dificuldades para a constituição de provas que evidenciem sua ocorrência e, também, para o estabelecimento do nexo causal entre o assédio e o dano à saúde das vítimas. Por fim, os advogados revelaram condutas inadequadas e que podem ser consideradas antiéticas, tais como a inclusão de falsas alegações de assédio moral, visando avultar valores indenizatórios por danos morais.

Os resultados da pesquisa que embasou este artigo têm implicações para enfrentamento do assédio moral no trabalho no nível judicial, na medida em que podem contribuir para a necessária qualificação da atuação de advogados diante da busca por indenização para os trabalhadores acometidos por esse tipo de violência. Do mesmo modo, os dados podem ser aplicados na formação acadêmica na área do direito trabalhista, já que sugerem entendimentos inadequados quanto à caracterização do assédio e quanto à questão das noções de assédio moral e dano moral. Este estudo ressaltou a necessidade de que o fenômeno do assédio moral seja enfrentado interdisciplinarmente, de modo a reduzir os impactos danosos à saúde dos trabalhadores, às organizações e sociedade. 
Para além das contribuições, este estudo limitou-se à investigação da compreensão do assédio moral por parte de um reduzido número de profissionais advogados, não abrangendo os demais operadores do direito. Pesquisas futuras podem incluir as demais categorias atuantes no contexto jurídico, como juízes, desembargadores, auditores e procuradores. Sugere-se, também, que pesquisas possam desenvolver e avaliar materiais educativos sobre o assédio moral para as categorias profissionais envolvidas no seu enfrentamento, como é o caso de advogados, de modo a contribuir, por conseguinte, com a prevenção e o enfrentamento do assédio moral no trabalho.

\section{Referências}

Adorno Júnior, H. L. (2010). Estabilidade do dirigente sindical: aspectos processuais. Universitas, 3(4), 83-96. http://revistauniversitas.inf.br/index.php/UNIVERSITAS/article/view/88/70

Antunes, R. \& Praun, L. (2015). A sociedade dos adoecimentos no trabalho. Serviço Social \& Sociedade, 123, 407-427. https://doi.org/10.1590/0101-6628.030

Araújo, A. R. (2008). O uso instrumental do assédio moral pelas organizações. In L. A. Soboll (Org.), Violência psicológica no trabalho e assédio moral: pesquisas brasileiras (pp. 75-92). Casa do Psicólogo.

Araújo, M. S. G. de. (2009). Preditores individuais e organizacionais de bullying no local de trabalho [Tese de Doutorado, Universidade do Minho, Portugal]. http:/hdl.handle.net/1822/11041

Arenas, M. V. S. \& Piccinini, V. C. (2012). Assédio moral nas relações de trabalho e a legislação vigente. Revista de
Administração
e
Negócios
da
Amazônia,
$4(2)$
$108-121$.

http://www.periodicos.unir.br/index.php/rara/article/view/491/554

Bardin, L. (2011). Análise de conteúdo. Edições 70.

Barreto, M. M. S. (2000). Uma Jornada de Humilhações [Dissertação de Mestrado, Pontifícia Universidade Católica de São Paulo, Brasil]. https://tede2.pucsp.br/handle/handle/17175

Battistelli, B. M., Amazarray, M. R., \& Koller, S. H. (2011). O assédio moral no trabalho na visão de operadores do direito. Psicologia ES Sociedade, 23(1), 35-45. https://doi.org/10.1590/S0102-71822011000100005

Bender, M. (2017). Violência simbólica no trabalho: análise da demanda judicial de assédio moral no estado do Rio Grande do Sul. Revista Brasileira de Sociologia do Direito, 4(2), 148-166. https://doi.org/10.21910/rbsd.v4n2.2017.152

Cassito, M. G., Fattorini, E., Gilioli, R., Rengo, C., \& Gonik, V. (2004). Sensibilizando sobre el acoso psicológico en el trabajo. In R. Gilioli, M. A. Fingerhut, \& E. Kortum-Margot (Eds.), Serie Protección de la Salud de los Trabajadores (Vol. 4, pp. 1-38). Organización Mundial de la Salud. https://apps.who.int/iris/bitstream/handle/10665/42660/9243590529.pdf

Casulo, A. C. (2018). O Brasil e a nova ordem neoliberal: impactos na saúde mental da classe trabalhadora. In A. C. Casulo, C. Silveira, G. Alves, \& P. S. Vasquez (Orgs.), Precarização do trabalho e saúde mental: o Brasil da era neoliberal (pp. 63-80). Projeto Editorial Praxis.

Cavalieri Filho, S. (2012). Programa de responsabilidade Civil (10aㅡ ed.). Atlas.

Coêlho, M. V. F. (2017). Comentários ao novo código de ética dos advogados. Saraiva.

Decreto-Lei no 5.452, de 1ำ de Maio de 1943. (1943). Aprova a Consolidação das Leis do Trabalho. Diário Oficial da União. http://www.planalto.gov.br/ccivil_03/decreto-lei/del5452.htm

Delgado, M. G. (2018). Curso de direito do trabalho (17ª ed., rev. atual. e ampl. LTr).

Evangelista, R. (2000). Algumas considerações sobre as perícias judiciais no âmbito cível. Revista IMESC, 2, 51-57.

Figueiredo-Ferraz, H., Gil-Monte, P. R., \& Olivares-Faúndez, V. E. (2013). Influence of mobbing (workplace bullying) on depressive symptoms: a longitudinal study among employees working with people with intellectual disabilities. Journal of Intellectual Disability Research, 59(1), 39-47. https://doi.org/10.1111/jir.12084 
Freitas, M. E. de. (2001). Assédio moral e assédio sexual: faces do poder perverso nas organizações. RAE-Revista de Administração de Empresas, 41 (2), 8-19. https://doi.org/10.1590/S0034-75902001000200002

Glina, D. M. R., \& Soboll, L. A. (2012). Intervenções em assédio moral no trabalho: uma revisão da literatura. Revista Brasileira de Saúde Ocupacional, 37(126), 269-283. https://doi.org/10.1590/s0303-76572012000200008

Gosdal, T. C. (2017). O entendimento do assédio moral e organizacional na justiça do trabalho. In L. A. P. Soboll (Org.), Intervenções em assédio moral e organizacional (pp. 23-32). LTr.

Guedes, M. N. (2004). Terror psicológico no trabalho (2 $2^{\mathrm{a}} \mathrm{ed}$.). LTr.

Guedes, J. G., Colussi, L. A., \& Grzybovsli, D. (2010). Responsabilidade pelos danos morais nos casos de assédio moral vertical nas relações de trabalho. In D. Grzybovski, A. R. Mozzato, \& A. D. S. Pereira (Orgs.), Assédio moral no trabalho: múltiplos olhares (pp. 147-184). IMED.

Heloani, R. (2005). Assédio moral: a dignidade violada. Aletheia, 22, 101-108. http://pepsic.bvsalud.org/scielo.php?script=sci_arttext\&pid=S1413-03942005000200010

Heloani, R. (2016). Assédio moral: ultraje a rigor. Revista direitos, trabalho e política social, 2(2), 29-42. http://revista91.hospedagemdesites.ws/index.php/rdtps/article/view/28

Hirigoyen, M. -F. (2002). Mal-estar no trabalho: redefinindo o assédio moral. Bertrand.

Jacques, M. da G. (2007). O nexo causal em saúde/doença mental no trabalho: uma demanda para a psicologia. Psicologia EF Sociedade, 19 (nspe.), 112-119. https://doi.org/10.1590/s0102-71822007000400015

Lei $n^{\circ}$ 8.212, de 24 de julho de 1991. (1991). Dispõe sobre a organização da Seguridade Social, institui Plano de Custeio, e dá outras providências. http://www.planalto.gov.br/ccivil_03/leis/18212cons.htm

Leymann, H. (1996). The content and development of mobbing at work. European Journal of Work and Organizational Psychology, 5(2), 165-184. https://doi.org/10.1080/13594329608414853

Lima, C. Q. B., Barbosa, C. M. G., Mendes, R. W. B., \& Patta, C. A. (2014). Assédio moral e violências no trabalho: caracterização em perícia judicial - relato de experiência no setor bancário. Revista Brasileira de Saúde Ocupacional, 39(129), 101-110. https://doi.org/10.1590/0303-7657000050313

Lima, T. D. F., \& Souza, M. A. de. (2015). O Impacto do mobbing sobre o estresse no trabalho. Estudos e Pesquisas em Psicologia, 15(2), 608-630. https://doi.org/10.12957/epp.2015.17661

Malhadas, M. J. O., Fiorelli, M. R., \& Fiorelli, J. O. (2015). Assédio moral: uma visão multidisciplinar (2ª ed.). Atlas.

Minayo, M. C. de S. (2014). O desafio do conhecimento: pesquisa qualitativa em saúde (14를. ed.). Hucitec.

Nelson, R. A. R. R. \& Teixeira, W. D. O. R. (2017). Da análise dos aspectos estruturantes do assédio moral laboral para sua configuração no sistema normativo Brasileiro. Prisma Juridico, 16(2), 392-427. https://doi.org/10.5585/prismaj.v16n2.7690

Notelaers, G., Heijden, V. B., Hoel, H., \& Einarsen, S. (2018). Measuring bullying at work with the short-negative acts questionnaire: identification of targets and criterion validity. Work $\mathcal{E}$ Stress, 33(1), 58-75. https://doi.org/10.1080/02678373.2018.1457736

Pamplona Filho, R. (2018). Noções conceituais sobre o assédio moral na relação de emprego. Revista eletrônica do Tribunal Regional do Trabalho da Bahia, 2(2), 1079-1089. https://hdl.handle.net/20.500.12178/148596

Pooli, A. M. \& Monteiro, J. K. (2018). Assédio moral no judiciário: Prevalência e repercussões na saúde dos trabalhadores. Revista Psicologia: Organizações e Trabalho, 18(2), 346-353. https://10.17652/rpot/2018.2.13516

Pretti, R. J. (2021). Legislação brasileira sobre o assédio moral no trabalho. Brazilian Journal of Development, 7(3), 23535-23543. https://doi.org/10.34117/bjdv7n3-185

Qureshi, M. I., Iftikhar, M., Janjua, S. Y., Zaman, K., Raja, U. M., \& Javed, Y. (2013). Empirical investigation of mobbing, stress and employees' behavior at work place: quantitatively refining a qualitative model. Quality EQ Quantity, 49(1), 93-113. https://doi.org/10.1007/s11135-013-9976-4 
Rezende, L. D. O. (2008). Revisitando os elementos estruturais do assédio moral: um caminho metodológico necessário para a correta compreensão do tema no âmbito jurídico. In L. A. P. Soboll (Org.), Violência psicológica e assédio moral no trabalho: pesquisas brasileiras (pp. 57-73). Casa do Psicólogo.

Rissi, V., Cecconello, W. W., \& Pauli, J. (2013). Psychological Violence in the management of health workers: a study from the Brazilian context. IJAME, 2(6), 1-5. https://www.managementjournal.info/index.php/IJAME/article/view/320

Rissi, V., Monteiro, J. K., Cecconello, W. W., \& de Moraes, E. G. (2016). Intervenções psicológicas diante do assédio moral no trabalho. Temas em Psicologia, 24(1), 339-352.

Soboll, L. A. P. (2008). Assédio moral no Brasil: a ampliação conceitual e suas repercussões. In L. A. P. Soboll (Org.), Violência psicológica e assédio moral no trabalho (pp. 23-55). Casa do Psicólogo.

Soboll, L. A. P. (2017). Assédio moral e organizacional na perspectiva psicossocial: critérios obrigatórios e complementares. In L. A. P. Soboll (Org.), Intervenções em assédio moral e organizacional (pp. 13-22). LTr.

Soboll, L. A., Miara, T., \& Moscalewsky, J. (2017). A questão da intencionalidade no assédio moral. Trabalho (En)Cena, 2(2), 03-17. https://doi.org/10.20873/2526-1487v2n2p3

Valadão, V. M. \& Mendonça, J. M. B. (2015). Assédio moral no trabalho: dilacerando oportunidades. Cadernos EBAPE.BR, 13(1), 19-39. https://doi.org/10.1590/1679-39519022

Vasquez, P. S. (2007). Constituição de Identidade da mulher no mundo do trabalho. In P. S. Vasquez \& V. S. Vasquez (Orgs.), Gênero, trabalho e saúde: a experiência das mulheres do setor calçadista na Bahia-passos para um futuro melhor (pp. 37-60). Fast Design.

Vasquez, P. S. (2018). Assédio moral no trabalho, sofrimento psíquico e luta por direitos. In A. C. Casulo, C. Silveira, G. Alves, \& P. S. Vasquez (Orgs.), Precarização do trabalho e saúde mental: o Brasil da era neoliberal (pp. 8395). Editorial Praxis.

Ventura, E. F., Teixeira, L. A. A., Oliveria, R. R., \& Porto, L. (2018). Assédio moral e seu dano na saúde mental dos indivíduos. Revista de Administração Hospitalar e Inovação em Saúde-RAHIS, 14(4), 56-72. https://doi.org/10.21450/rahis.v14i4.4757

\section{Endereço para correspondência} morganazamarchi@hotmail.com
Recebido em: 24/06/2020

Revisado em: 29/04/2021

Aprovado em: 17/05/2021 